\title{
Review
}

Sena Cantas-Orsdemir*, Jane L. Garb and Holley F. Allen

\section{Prevalence of cranial MRI findings in girls with central precocious puberty: a systematic review and meta-analysis}

https://doi.org/10.1515/jpem-2018-0052

Received January 29, 2018; accepted May 14, 2018; previously published online June 14, 2018

\begin{abstract}
Background: Some pediatric endocrinologists recommend that girls with central precocious puberty (CPP) have cranial magnetic resonance imaging (MRI) performed only if they are younger than 6 years of age. However, no practice guidelines exist. The objective of this review was to assess the frequency of intracranial lesions in girls with CPP.

Content: We searched six electronic databases (PubMed, Cochrane, Web of Science, SCOPUS, ProQuest, and Dissertation \& Theses) from 1990 through December 2015. We included studies on girls with CPP and MRI data. Case reports, case series, studies from the same author/group with the same patient population, and studies with conditions predisposing to CPP were excluded. Two physicians independently reviewed the search results and extracted data. A random-effects model was used to obtain pooled prevalence of positive MRI's across studies. Heterogeneity among studies was evaluated with the Q-statistic. Publication bias was assessed with funnel plots and Egger's test. Pooled prevalence was computed by age group. A linear regression assessed the relationship between intracranial lesion prevalence and healthcare availability. We included 15 studies with a total of 1853 girls $<8$ year old evaluated for CPP.
\end{abstract}

Summary: The pooled prevalence from all studies was 0.09 [95\% confidence interval (CI) 0.06-0.12]. There was a significant heterogeneity, indicating the appropriateness of a random effects model in computing pooled prevalence. In

\footnotetext{
*Corresponding author: Sena Cantas-Orsdemir, MD, University of California Irvine, School of Medicine, Department of Pediatrics/ Division of Pediatric Endocrinology, 333 City Blvd West, City Tower \#800, Orange, CA 92868, USA, Phone: +919-259-2681,

E-mail: senacantas@gmail.com

Jane L. Garb: UMMS-Baystate Medical Center, Division of Academic Affairs, Springfield, MA, USA

Holley F. Allen: UMMS-Baystate Medical Center, Department of Pediatrics, Division of Pediatric Endocrinology, Springfield, MA, USA
}

the few studies stratified by age group, pooled prevalence was $25 \%$ in girls $<6$ years vs. $3 \%$ in girls $6-8$ of age.

Outlook: Our results support that the benefit of routine MRIs in girls with CPP older than 6 years of age without any neurological concerns is not clear-cut.

Keywords: central precocious puberty (CPP) and magnetic resonance imaging (MRI); CPP and neuroimaging; precocious puberty work-up; precocious puberty and neuroimaging.

\section{Introduction}

Precocious puberty (PP) has been defined by the development of secondary sexual characteristics before the age of 9 years in boys and 8 years in girls [1-6]. If PP occurs due to the activation of the hypothalamic-pituitary gonadal axis, it is termed as central precocious puberty (CPP). CPP can be idiopathic due to genetic mutations or is associated with central nervous system (CNS) abnormalities, such as hamartomas or brain tumors. CPP can be treated with gonadotropin (GnRH) agonists in order to prevent short final adult height and psychological effects on the child $[1,6]$.

The definition of PP is based on studies from the 1960s [2]. The age at which girls are considered to have PP has been questioned, as several studies have shown that normal girls have been entering puberty earlier for the past two decades [7-14]. In 1997, a large epidemiologic US study with $>17,000$ girls indicated that breast and pubic hair development were occurring significantly earlier than in the past [15]. Following this study, a letter published in the journal Lancet by a group of pediatric endocrinologists proposed revising the guidelines for the age at which PP should be investigated [16]. The Pediatric Endocrine Society issued recommendations in 1999 for PP, lowering the age threshold from 8 to 7 years for White girls and to 6 years for Black girls [17]. However, 8 years continues to be a commonly-used threshold for the definition of PP [18-23].

Once CPP is confirmed with laboratory testing, CNS imaging is considered to rule out the presence of CNS abnormalities. The prevalence of CNS abnormalities in boys is 
reported to be as high as $40-75 \%$ [20, 24]. Therefore, it is recommended that all boys with PP have brain magnetic resonance imaging (MRI). However, the prevalence of CNS abnormalities in girls is much lower, varying between $0 \%$ and $27 \%$ among different studies and decreases with increasing age [21-23]. Because some of these prevalence rates include incidental lesions, the prevalence of brain tumors and other progressive pathologies is even smaller [23]. Based on these data and in light of discussions regarding the decreasing age of normal puberty, it is hard to justify routine brain MRI in all girls presenting with puberty before age 8. It has been suggested that girls with CPP should have a brain MRI performed routinely only if they are younger than 6 years of age [1]. However, cranial MRI continues to be performed routinely in many centers for all the girls presenting with breast development before the age of 8 due to the risk of finding an occult intracranial lesion.

Brain MRIs are expensive and potentially harmful due to administration of contrast agents as well as IV sedation which is often needed in young children [25]. Other considerations are increased anxiety in children, and in parents, and the possibility of finding an incidental lesion which is not related to CPP but increases the need for follow-up imaging studies and follow-up visits, as well as healthcare cost.

\section{Objective of the study}

The aim of this study was to perform a meta-analysis of the prevalence of intracranial lesions detected with brain MRI in girls with CPP. The secondary aim was to stratify this data by age groups to better understand the risk of finding an intracranial lesion in girls with CPP who are older than 6 years of age. We also tested the relationship between the availability of healthcare measured by physician density according to geographic locale and the risk of finding of an intracranial lesion in girls presenting with CPP.

\section{Materials and methods}

\section{The prevalence of intracranial lesions detect- ed with cranial MRI in girls with CPP}

\section{Definition of central precocious puberty}

PP secondary to the activation of the hypothalamic-pituitary-gonadal axis is termed as CPP. Several hormone measurements have been used to confirm the diagnosis of CPP. The use of a GnRH stimulation test is the most common confirmatory test and a stimulated luteinizing hormone $(\mathrm{LH})>5$ or LH/follicle-stimulating hormone $(\mathrm{FSH})>0.66$ is considered pubertal by many endocrinologists $[4,26]$. With the increasing sensitivity of LH assay, a basal LH level is now used in many centers. An LH level $>0.2-0.3$ (depending on the assay) is consistent with CPP [27, 28].

\section{Search strategy for systematic review}

In December 2015, PubMed, Cochrane, Web of Science, SCOPUS, ProQuest, and Dissertation and Theses were searched in cooperation with a specialized reference librarian to identify potentially relevant articles (Supplemental Material, Appendix 1). References of key articles were also screened to identify potentially eligible articles. A final literature review was conducted in February 2017 to include the most recent publications but no additional studies meeting our criteria were found.

\section{Eligibility criteria}

We included original studies with a study population including girls diagnosed with CPP using the definition of PP as development of secondary sexual characteristics before age 8 which included MRI data, regardless of the original question of the study. Studies published after 1990 were evaluated for inclusion because MRI became the preferred method of imaging to screen CNS lesions in the early 1990s. Inclusion of articles was not restricted to those written in English. A few of the included studies either did not specify which girls had MRI vs. computed tomography (CT), or used CT for selected girls in whom MRI was contraindicated. All case reports and case series, studies from the same author/group which might potentially include the same patient population, and studies with patients who were previously known to have CNS lesions or conditions known to increase the risk of CPP were excluded. Articles with a subset of patients meeting the criteria were included if data were extractable.

\section{Data screening and extraction}

After a de-duplication process (Supplemental Material, Appendix 2), all identified articles were first screened by title only to exclude clearly irrelevant articles [29]. The remaining articles were then screened by abstracts and full texts as needed. Finally, selected article's full texts were reviewed in detail before inclusion in the meta-analysis (Table 1). Two different authors (SO, HA) performed 
Table 1: Study characteristics.

\begin{tabular}{|c|c|c|c|c|c|c|c|}
\hline Author & Year & Country & Diagnostic criteria & Imaging modality & Years of enrollment & $\mathbf{n}$ & Group \\
\hline Kao & 1992 & US & Not specified & MRI & 1987-1991 & 14 & Rad \\
\hline Bridges & 1994 & UK & GnRH stim test & MRI & $1975-1990$ & 85 & Endo \\
\hline Cisternino & 2000 & Italy & GnRH stim test & CT or MRI & $1988-1988$ & 274 & Endo \\
\hline Bajpai & 2002 & India & Baseline LH, FSH/GnRH stim test & $M R I^{a}$ & $1990-2000$ & 77 & Endo \\
\hline $\mathrm{Ng}$ & 2003 & UK & GnRH stim test & MRI & $1990-2001$ & 67 & Endo \\
\hline Chalumea & 2003 & France $^{b}$ & b & $\mathrm{CT}$ or $\mathrm{MRI}^{\mathrm{C}}$ & b & 443 & Endo \\
\hline Grunt & 2004 & US & Baseline LH, FSH & MRI & 1987-1996 & 75 & Endo \& Rad \\
\hline Lee & 2009 & Taiwan & GnRH stim test & MRI & $1985-2007$ & 179 & Endo \\
\hline Jaruratanasirikul & 2010 & Taiwan & Baseline LH, FSH & MRI & $1995-2009$ & 68 & Endo \\
\hline Jakubowska & 2011 & Poland & GnRH stim test & MRI & 1999-2009 & 36 & Endo \& Rad \\
\hline Mogensen & 2012 & Denmark & GnRH stim test & MRI & $1993-2009$ & 104 & Endo \& Rad \\
\hline Shiva & 2012 & Iran & Baseline LH, FSH & MRI & $2007-2009$ & 38 & Endo \\
\hline Atta & 2013 & Pakistan & GnRH stim test & MRI & 2009-2011 & 26 & Endo \\
\hline Pedicelli & 2014 & Italy & GnRH stim test & MRI & $1990-2012$ & 167 & Endo \\
\hline Kim & 2016 & Korea & Not specified & MRI & $2005-2015$ & 200 & Endo \\
\hline
\end{tabular}

aFive patients had CT. ${ }^{\mathrm{b}}$ Multicenter study, varies based on the center. ${ }^{\mathrm{C}}$ Thirty-nine patients did not have imaging but were followed for $>2$ years and did not have any health concerns. Endo, endocrinology; Rad, radiology.

both the screening of the title, abstracts and the review in detail. Cross-checking was conducted for consistency. The Preferred Reporting Items for Systematic Reviews and Meta-Analyses (PRISMA) statement was used for reporting [30].

The following data were extracted from selected studies using a pre-designed extraction form: (1) general information, including authors, publication year, country; (2) total number of girls who had an MRI during evaluation of CPP; (3) total number of girls found to have CNS lesions; (4) age range of patients; (5) characteristics of reported brain lesions. We attempted to contact authors of the articles included in the meta-analysis via e-mail to gather unpublished data, especially regarding the age information in order to analyze data based on age groups of $<6$ and $6-8$, and $<7$ and $7-8$.

A detailed review of these articles revealed that certain lesions were classified as incidental by some groups while classified as pathologic by others. In order to sort this out, all brain lesions reported in these 15 articles were listed and re-grouped. A rathke's cleft cyst, empty sella, pituitary microadenoma and isolated stalk thickening were the lesions for which there was no clear consensus on the relationship with CPP [31-33]. We re-ran the meta-analysis after placing these lesions in "questionable relationship with CPP” category (Table 2).

\section{Bias assessment}

A visual inspection of funnel plots was supplemented with Egger's test of symmetry to assess bias.

\section{Statistical analysis}

All analyses were performed using the METAN procedure in STATA [34]. The prevalence of positive MRIs and an exact binomial 95\% confidence interval [35] was computed for each study. A composite or pooled estimate of the prevalence for all studies combined was computed and it represents the weighted average of the prevalence from individual studies, weighted by the sample size and variability of each study. Studies with greater sample sizes contributed more to the estimate than smaller studies. The precision of the pooled estimate (i.e. a 95\% confidence interval) was a function also, in part, of the population size of each study.

In the absence of any consensus in the literature for the prevalence of positive MRI findings in these children (which is in fact the motivation for our meta-analysis), we used the standard null hypothesis that the prevalence is zero. Rejecting this hypothesis would lead to the conclusion that MRI's do yield positive findings in a portion of children. We used the confidence interval of the pooled proportion as a test of this hypothesis. If the lower limit of the $95 \%$ confidence interval is above zero, we will conclude that it is statistically significant.

The Q-statistic was used to test for heterogeneity among studies in prevalence and sample size [36]. In the presence of significant heterogeneity, a random effects model [37] was used with a continuity correction to handle zero proportions (prevalence). A random effects model assumes that studies are sampled from a larger population or different populations with different prevalences. The variance of the pooled prevalence under this model is a function of both within and among-study variability, 
Table 2: Characteristics of MRI findings in the study population.

\begin{tabular}{|c|c|c|}
\hline $\begin{array}{l}\text { Pathological findings } \\
(\mathrm{n}=142)\end{array}$ & $\begin{array}{l}\text { Questionable relationship with CPP } \\
(n=42)\end{array}$ & $\begin{array}{l}\text { Incidental findings } \\
(n=50)\end{array}$ \\
\hline Agenesis of corpus callosum (1) & Empty Sella (13) & Absence of bright spot (2) \\
\hline Arachnoid cyst (12) & Pituitary microadenoma (22) & Arnold Chiari Malformation (2) \\
\hline Astrocytoma (15) & Rathke’s cleft cyst (4) & Cavum vergae cyst (1) \\
\hline Craniopharyngeoma (4) & Isolated stalk thickening (3) & Choroid plexus cyst (2) \\
\hline Glioma (4) & & Cyst of pars intermedia (4) \\
\hline Hypothalamic teratoma (1) & & Dilated Virchow spaces (1) \\
\hline Hypothalamic tumor (1) & & Enlarged cisterna magna (1) \\
\hline Hypothalamic hamartoma (68) & & Gliosis (2) \\
\hline Hydrocephalus (10) & & Hypomyelination in trigonal region (1) \\
\hline Meningitis (1) & & Increase in pituitary volume (21) \\
\hline Neurofibromatosis (1) & & Lipoma of the lamina quadrigemina (1) \\
\hline Neurotuberculosis (4) & & Pineal cyst (4) \\
\hline Periventricular leukomalacia (1) & & Pituitary stalk deviation (5) \\
\hline Intracranial hypertension (1) & & Pseudocyst of the sphenoid bone (1) \\
\hline Pontine tumor (1) & & Spinal fluid-like area in the posterior \\
\hline Pinealoma (1) & & wall (1) \\
\hline Pituitary hypoplasia (6) & & Vascular malformation (1) \\
\hline \multicolumn{3}{|l|}{ Suprasellar tumor (1) } \\
\hline \multicolumn{3}{|l|}{ History of radiotherapy (1) } \\
\hline \multicolumn{3}{|l|}{ 4th ventricular tumor (1) } \\
\hline Unknown (7) & & \\
\hline
\end{tabular}

Incidental lesions from Mogensen et al.'s paper was not extractable and was not included in this table. Tumors are in bold.

resulting in a larger (more conservative) standard error and a wider confidence interval for the pooled prevalence than under a fixed effects model. The confidence interval is used to determine statistical significance, i.e. if the $95 \%$ confidence interval for the pooled estimate of prevalence is above 0 , we will conclude that the estimated percentage of positive findings was significantly more than zero.

\section{Sub-group analysis of the prevalence of CNS lesions in different age groups}

The pooled prevalence of intracranial lesions stratified by age groups $<6$ vs. $6-8$, and $<7$ vs. $7-8$ was reported descriptively, due to the small number of studies where such stratification could be performed.

Additionally, the percentage of tumors was calculated to understand the incidence of lesions that will require intervention when found during MRI imaging of the brain in girls with CPP.

\section{Relationship between the prevalence of CNS lesions and availability of healthcare}

Data describing physician density (MD/1000 population) was gathered from a World Health Organization (WHO) report conducted in 2008-2014 [38]. We used a linear regression to assess the relationship between physician density and the prevalence of CNS abnormalities in girls presented with CPP.

This research is not related to either human or animal use.

\section{Results}

\section{The prevalence of intracranial lesions detected with cranial MRIs in girls with CPP}

\section{Search results}

Our initial literature search in December 2015 identified 2818 articles, and 1392 unique articles remained after deduplication. We excluded 1264 articles after screening by titles including case reports/series, articles studied patient population with underlying conditions known to predispose to PP, articles which studied only boys and those with clearly irrelevant topics leaving 128 articles. Two additional articles were identified via screening citation lists of selected articles. Among these, 130 articles, 96 articles were excluded after screening by abstracts and full texts as needed due to not having any imaging data 


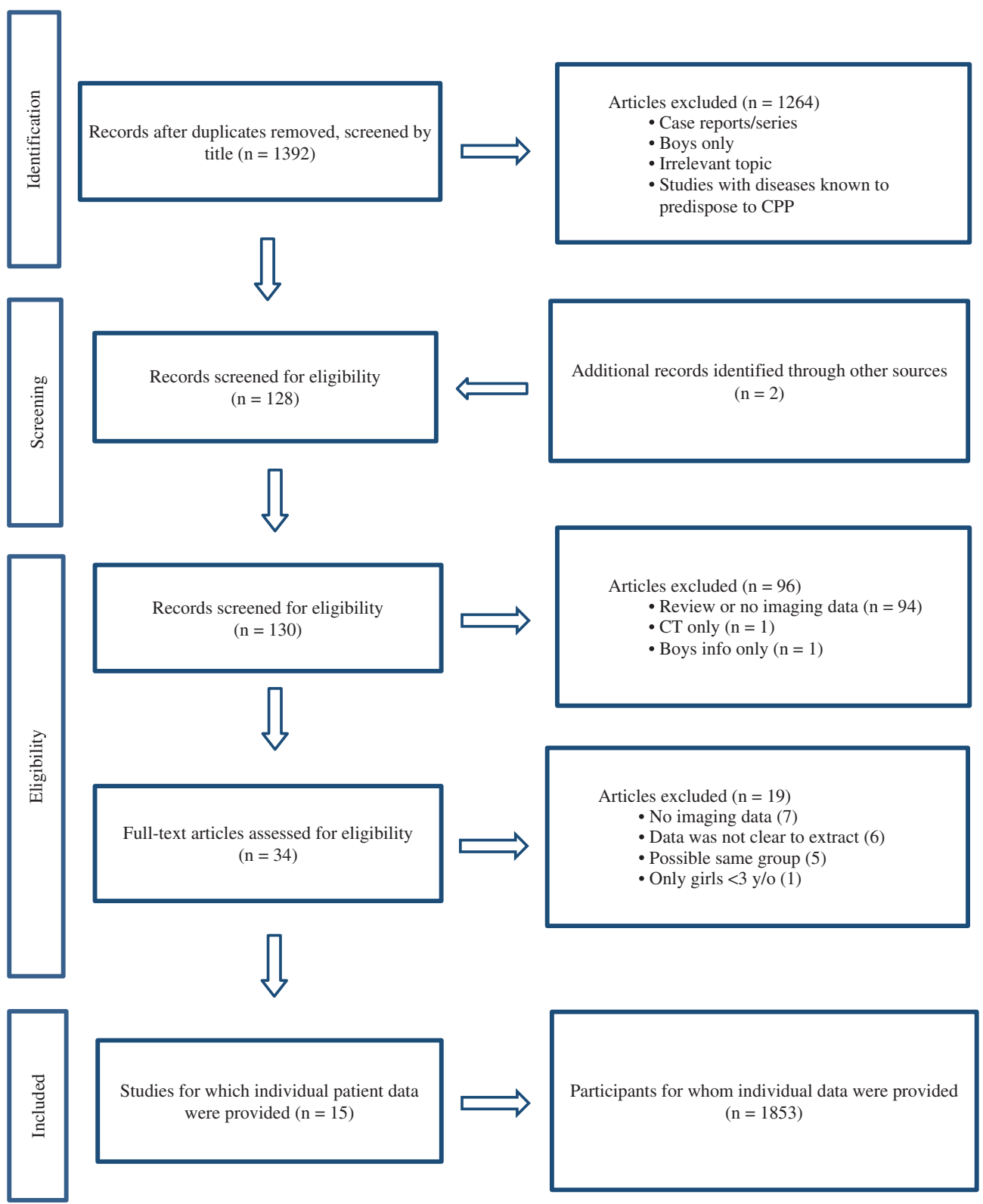

Figure 1: A flow diagram illustrating the process by which articles were included or excluded in the study.

$(\mathrm{n}=94)$, reporting data only with CT imaging $(\mathrm{n}=1)$ and boys only $(n=1)$. We reviewed a total of 34 articles full-text for inclusion. Fifteen articles were included in this metaanalysis. No further articles were identified by final literature review in March 2017 (Figure 1).

\section{Study characteristics}

The study characteristics are shown in Table 1. Included studies were published between 1990 and 2015. There were data from a total of 1853 patients extracted from 15 articles.

\section{Meta-analysis}

There was a significant heterogeneity (variability) in the prevalence of positive MRI and sample size among the studies (Q-statistic $=57.0, \mathrm{df}=14, \mathrm{p}<0.01$ ). Therefore, $\mathrm{a}$ random effects model was used to pool the prevalence estimates. The estimated proportion of positive MRIs across all studies was 0.09 (95\% CI 0.06-0.12), which was statistically significant at the 5\% level (Figure 2).

When all findings were re-examined and the lesions with questionable relationship with CPP excluded, there was still significant heterogeneity in the prevalence 


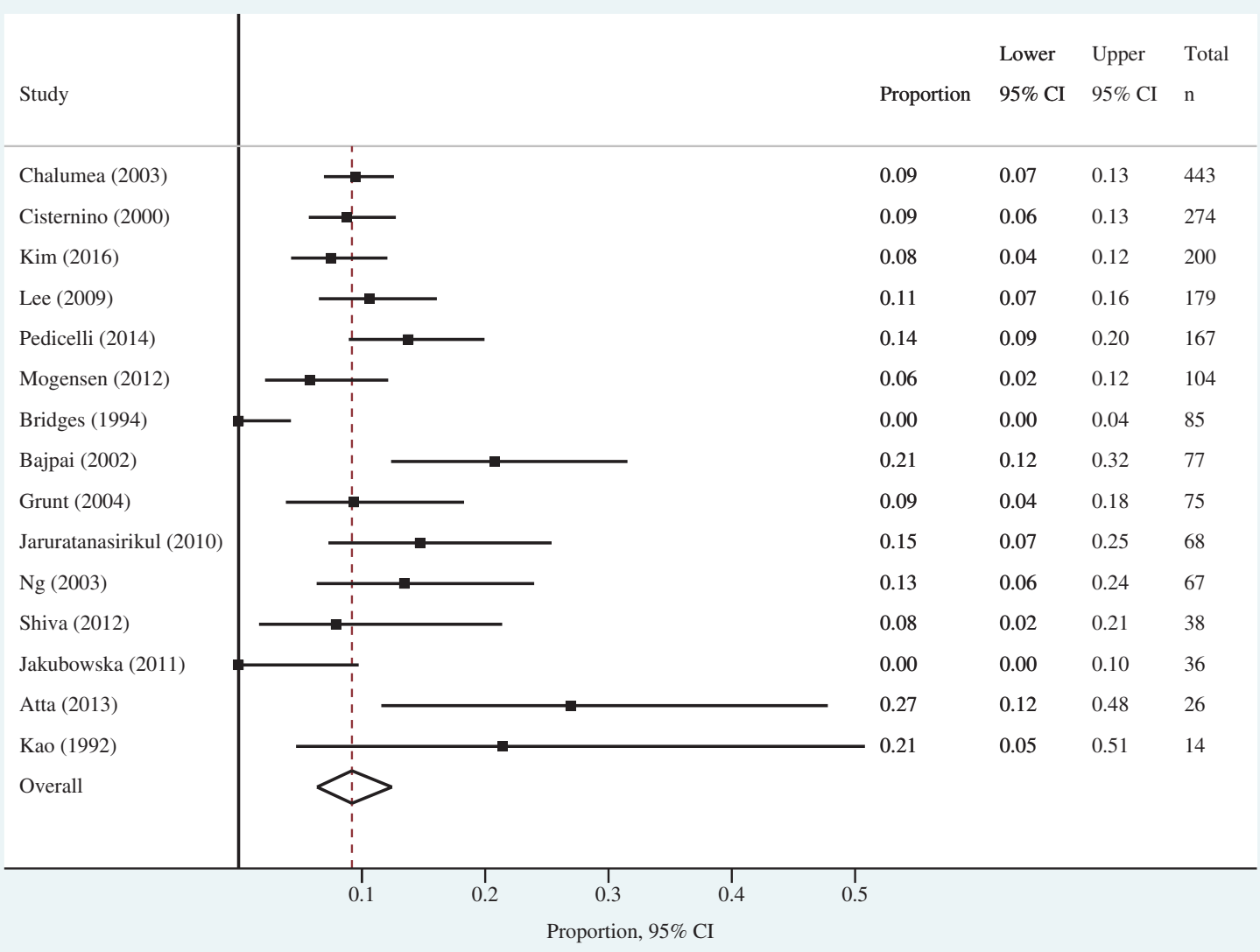

Figure 2: Forest plot of the proportion of the girls $<8$ with positive MRI findings.

among the studies $\left(\chi^{2}=60.7, \mathrm{df}=14, \mathrm{p}<0.01\right)$. The pooled random-effects estimate for the proportion of positive MRI's decreased to 0.07 (95\% CI 0.05-0.10). This was significantly greater than zero $(\mathrm{z}=8.4, \mathrm{p}<0.01)$.

\section{Risk of bias}

Egger's test showed no significant asymmetry or presence of small-study bias when all intracranial lesions were included in the analysis and after intracranial lesions with questionable relationships with CPP were excluded ( $\mathrm{p}=0.37$ and $\mathrm{p}=0.15$, respectively).

Funnel plots are graphs used to assess the presence of bias in the selection of studies for publication [39]. The effect size (in this case, proportion of positive MRI's) for each study is plotted on the $\mathrm{x}$-axis and its sample size on the y-axis. If there is no publication bias, and all studies came from the same population with a common effect size, effect size is solely a function of sample size and large studies should be more likely to report large effect sizes (producing significant results) than smaller studies.
This results in an inverted funnel-shaped plot (with the point at the top) symmetrical about the mean effect size. The absence of this shape signifies that effect sizes are independent of sample size, which is evidence of publication bias because publication bias will inflate the number of large effect sizes among smaller studies.

The funnel plot conforms to the basic inverted funnel shape, indicating the absence of bias, with the exception of missing points in the lower left. This indicates a potential bias for smaller studies with small prevalence not included, leading to a slight over-estimation of pooled prevalence. The bias introduced by this would be small, as small studies contribute little weight to the pooled estimate (Supplemental Material, Appendix 3).

\section{Sub-group analysis of the prevalence of intracranial lesions in different age groups}

We were not able to obtain any unpublished data after making multiple attempts to reach to the authors. The age data were extractable from only five of the articles. When data 
Table 3: Subgroup analysis.

\begin{tabular}{|c|c|c|c|c|c|c|c|c|}
\hline Author & $<6$ years old, $n$ & $\begin{array}{r}\text { Positive } \\
\text { MRI, n }\end{array}$ & $\%$ & $\begin{array}{r}\text { [95\% Confidence } \\
\text { interval] }\end{array}$ & $6-8$ years old, $n$ & $\begin{array}{r}\text { Positive } \\
\text { MRI, n }\end{array}$ & $\%$ & $\begin{array}{r}\text { [95\% Confidence } \\
\text { interval] }\end{array}$ \\
\hline Bajpai & 30 & 9 & 0.3 & $0.15-0.49$ & 47 & 7 & 0.15 & $0.06-0.28$ \\
\hline Chalumea & 108 & 29 & 0.27 & $0.19-0.36$ & 335 & 6 & 0.02 & $0.01-0.04$ \\
\hline Pedicelli & 35 & 6 & 0.17 & $0.07-0.34$ & 132 & 0 & 0 & $0-0.03$ \\
\hline \multirow[t]{2}{*}{ Overall } & & & 0.25 & $0.19-0.32$ & & & 0.03 & $0.00-0.1$ \\
\hline & $<7$ years old, $n$ & & & & $7-8$ years old, $n$ & & & \\
\hline Cisternino & 125 & 14 & 0.11 & $0.06-0.18$ & 149 & 12 & 0.08 & $0.0-0.14$ \\
\hline Chalumea & 202 & 31 & 0.15 & $0.11-0.21$ & 241 & 4 & 0.02 & $0.00-0.04$ \\
\hline Grunt & 42 & 7 & 0.17 & $0.07-0.31$ & 33 & 2 & 0.06 & $0.01-0.2$ \\
\hline Pedicelli & 103 & 6 & 0.06 & $0.02-0.12$ & 64 & 0 & 0 & $0.00-0.06$ \\
\hline Overall & & & 0.12 & $0.07-0.17$ & & & 0.03 & $0.00-0.08$ \\
\hline
\end{tabular}

were divided based on $<6$ and $6-8$ age groups, there were 173 girls who were $<6$ years old, and 514 girls who were $6-8$ years of age. The pooled prevalence of intracranial lesions was 0.25 $(0.19-0.32)$ in girls $<6$ years old, and $0.03(0.03-0.1)$ in girls $6-8$ years old. When data were stratified into $<7$ and $7-8$ age groups, there was a total of 472 girls $<7$ years old and 487 girls $7-8$ years old. The pooled prevalence of intracranial lesions was $12 \%(0.07-0.17)$ in girls $<7$ years old and 3\% (0.0-0.8) in girls 7-8 years old (Table 3 ).

In this patient pool of 1853 patients, the incidence of tumors was found to be $1.6 \%$. These tumors were astrocytomas, gliomas, craniopharyngiomas, suprasellar tumors, hypothalamic tumors, pontine tumor, pinealoma and 4th ventricular tumor (Table 2).

\section{Relationship between the prevalence of CNS lesions and availability of healthcare}

We hypothesized that patients in countries with limited access to healthcare would be less likely to seek medical care for signs of early puberty unless they also experienced other health concerns such as headache, weakness or visual abnormalities. Therefore, when they seek medical care with early signs of puberty, it would be more likely that they would have an intracranial lesion compared to their counterparts in developed countries. This might also explain some of the heterogeneity in our study. We found a non-significant trend of highly variable data points with this direction $\left(\mathrm{R}^{2}=0.17, \mathrm{p}=0.12\right)$ (Figure 3 ).

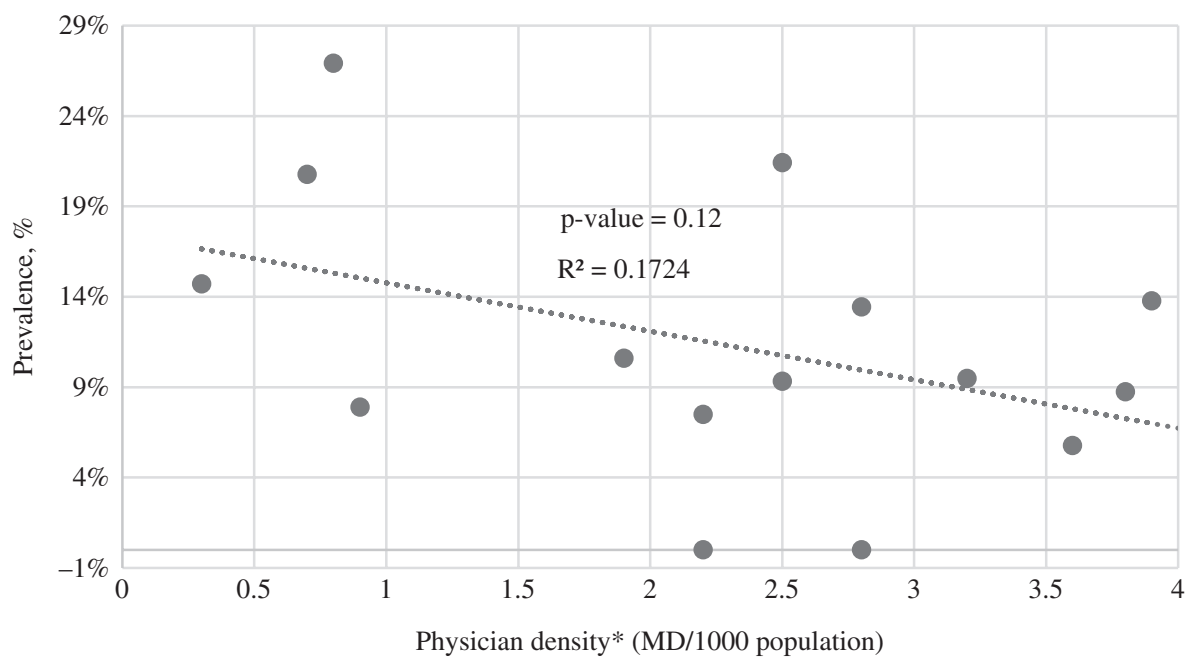

*WHO Global Health Observatory (GHO) data/Country statistics [38].

Figure 3: Physician density vs. prevalence of intracranial lesions. 


\section{Discussion}

We performed a systematic review and meta-analysis of the prevalence of patients who were found to have intracranial lesions using MRI during the work-up for PP. The overall prevalence of CNS lesions was found to be 9\% (95\% CI 0.06-0.12) when all the patients less than 8 years old with CPP were included in the analysis. This decreased to $7 \%$ when data were re-analyzed after examining all the brain lesions and eliminating those whose relationships with CPP were not clear. The biggest single group of abnormal findings was the hypothalamic hamartoma. Studies have found that hypothalamic hamartoma is almost exclusively found in girls with CPP diagnosed at less than 6 years of age. Moreover, finding a hamartoma supports the diagnosis of CPP but would not require any treatment other than standard GnRH agonist therapy. The incidence of tumors which would require intervention was found to be $1.6 \%$.

A subgroup analysis revealed a higher overall prevalence of intracranial lesions in girls who were $<6$ years of age as compared to 6-8 years of age. A similar trend continued to be observed in $<7$ vs. $7-8$ years old group as seen in previous studies [18, 23]. We found a slight nonsignificant trend toward higher prevalence of intracranial lesions in girls with CPP in countries with limited access to healthcare, which might be explained by delayed medical evaluation in the setting of limited availability.

The age cut-off for female PP derives from studies published in 1960s and data based on the children evaluated prior to that [2]. There has been a great controversy over the past three decades regarding the trend of decreasing age of puberty. Many studies, most of which were included in this meta-analysis, show that the incidence of brain lesions in girls older than 6 years of age with CPP is low $[17,18,40]$ and authors suggest performing cranial MRI in selected cases only. On the other hand, there are many other studies claiming the opposite [41, 42].

Following the publication of the US study in 1999 proposing a cut-off of 7 years for evaluation of PP [17], Chalumeau et al. examined whether this approach would miss important CNS lesions. In 197 girls with CPP, 11 (6\%) had an intracranial lesion. The prevalence of intracranial lesions was $19 \%$ in girls with onset under age 6, and $2 \%$ in patients between the ages of 6 and 8 . Based on the data from this study, the authors developed an algorithm to identify girls at a lower risk and reported that age $<6$ years or estradiol $>45$ th percentile identified all girls with organic brain lesions and they applied this algorithm to a larger group of patients from multiple centers in Europe [43]. In this larger population, they found a very similar prevalence of organic brain lesions. Only $2 \%$ of girls with
CPP had an organic lesion in the age group $6-8$, but for the group with puberty onset before age 6 , the prevalence was $29 \%$. In 2000, Cisternino et al. reported a rate of $8.7 \%$ in 274 girls, with a neoplasm rate of $2 \%$ [44].

In 2006, Stanhope et al. published an editorial and stated that it would be unfortunate to miss the diagnosis of early and treatable intracranial tumors and he suggested that newer age limits for the diagnosis of PP should be used with caution. In 2007, a consensus paper on the use of GnRH analogs in children was published in Pediatrics, stating that the likelihood of finding an organic brain lesion decreases by age and stated "Girls with CPP at $<6$ years of age should have a head MRI. It is controversial whether all girls who develop CPP between 6 and 8 years of age require head MRI. Girls with neurologic findings and rapid pubertal progression are more likely to have intracranial pathology and require an MRI examination".

Our study supports the decreasing trend of the prevalence of intracranial lesions by age and the idea that there are few girls with CPP older than 6 years of age with intracranial lesions. We agree with Kaplowitz who recently published a review article describing the low prevalence of intracranial lesions requiring intervention in the 6-8 year age group. He suggested that cranial MRI should be performed only in selected cases in this age group while notifying parents of the low likelihood of finding an intracranial tumor [45].

To the best of our knowledge, this is the first metaanalysis providing an overall estimate of the prevalence of intracranial lesions in girls with CPP. These data are important to describe the overall prevalence especially in the setting of a wide range of estimates. There is a high heterogeneity among studies possibly due to the wide age range, differences in quality of imaging techniques and variability between the features of patients included from each center. Also, the variability of cut-off for baseline LH level or LH/FSH ratio following a GnRH stimulation test differs in different centers, as well as assay quality. Even though we tried to ensure that all patients were diagnosed with CPP based on the same criteria, it was not possible to guarantee a homogenous group of patients. It was unfortunate not to be able to gather further data to analyze and understand better the differences between different age groups. One of the studies was conducted by a radiology group, which is subject to selection bias.

MRIs are expensive. A cranial MRI typically costs about $\$ 1000-\$ 5000$, depending on the patient's geographical location. The cost is not limited to the procedure but also includes the charge for the neuroradiologist interpreting the study, the charge for sedation when needed, and the charge due to follow-up MRIs and subspecialty visits in 
the case of an incidental finding. MRIs do not expose the child to ionizing radiation; however, there is a potential harm from the radiocontrast agents used during MRI imaging. The US Food and Drug Administration (FDA) is currently investigating the risk of brain deposits caused by gadolinium-based contrast agents used for MRI. They published a statement in 2015 and urged all the healthcare professionals' to re-assess the need for MRI [19]. The concerns for unnecessary MRIs are not limited to long-term side effects and cost, but include parental and patient anxiety. When an incidental finding is detected, there is a need for additional MRIs and sub-specialist visits to monitor incidental lesions which increase the degree of patient and parental anxiety, also resulting in missed school and work days.

There is little debate that all girls with CPP with onset before age 6 , and any girl with clinical findings indicating the possibility of an intracranial lesion need brain imaging. However, a majority of girls referred to pediatric endocrinologists and diagnosed with CPP are in the 6-8 age group and have no CNS-related symptoms. Our study showed the decreasing trend of the prevalence of intracranial lesions by age and supports the idea that there are few girls who are older than 6 years of age will be found to have an intracranial lesion.

\section{Conclusions}

Our results support that the benefit of routine MRIs in girls with CPP older than 6 years of age without any neurological concerns is not clear-cut. Intracranial pathology requiring intervention is a rare finding in girls with CPP older than 6 years. We should balance the potential risks and cost of healthcare against the likelihood of detecting an intracranial lesion requiring intervention at an earlier age than it would otherwise present.

Acknowledgments: The authors thank to Dr. Edward Reiter for his valuable advices.

Author contributions: All the authors have accepted responsibility for the entire content of this submitted manuscript and approved submission.

Research funding: None declared.

Employment or leadership: None declared.

Honorarium: None declared.

Competing interests: The funding organization(s) played no role in the study design; in the collection, analysis, and interpretation of data; in the writing of the report; or in the decision to submit the report for publication.
Prior presentations: Preliminary data was presented in abstract form at the PES 2016 Annual Meeting, Scientific Poster Session and Presidential Poster Session, Baltimore, MD, USA.

\section{References}

1. Carel JC, Eugster EA, Rogol A, Ghizzoni L, Palmert MR. Consensus statement on the use of gonadotropin-releasing hormone analogs in children. Pediatrics 2009;123:e752-62.

2. Marshall WA, Tanner JM. Variations in pattern of pubertal changes in girls. Arch Dis Child 1969;44:291-303.

3. Wheeler MD, Styne DM. Diagnosis and management of precocious puberty. Pediatr Clin North Am 1990;37:1255-69.

4. Brito VN, Latronico AC, Arnhold IJ, Mendonça BB. Update on the etiology, diagnosis and therapeutic management of sexual precocity. Arq Bras Endocrinol Metab 2008;52:18-31.

5. Partsch CJ, Heger S, Sippell WG. Management and outcome of central precocious puberty. Clin Endocrinol (Oxf) 2002;56:129-48.

6. Klein KO. Precocious puberty: who has it? Who should be treated? J Clin Endocrinol Metab 1999;84:411-4.

7. Sun SS, Schubert CM, Chumlea WC, Roche AF, Kulin HE, et al. National estimates of the timing of sexual maturation and racial differences among US children. Pediatrics 2002;110:911-91.

8. Aksglaede L, Sorensen K, Petersen JH, Skakkebaek NE, Juul A. Recent decline in age at breast development: the Copenhagen puberty study. Pediatrics 2009;123:e932-9.

9. Danubio ME, De Simone M, Vecchi F, Amicone E, Altobelli E, et al. Age at menarche and age of onset of pubertal characteristics in 6-14-year-old girls from the Province of L'Aquila (Abruzzo, Italy). Am J Hum Biol 2004;16:470-8.

10. Lindgren G. Pubertal stages 1980 of Stockholm school children. Acta Paediatr 1996;85:1365-7.

11. Fredriks AM, van Buuren S, Burgmeijer RJ, Meulmeester JF, Beuker RJ, et al. Continuing positive secular growth change in The Netherlands 1955-1997. Pediatr Res 2000;47:316-23.

12. Huen KF, Leung SS, Lau JT, Cheung AY, Leung NK, et al. Secular trend in the sexual maturation of southern Chinese girls. Acta Paediatr 1997;86:1121-4.

13. Rosenfeld RL, Bachrach LK, Chernausek SD, Gertner JM, Gottschalk $M$, et al. Current age of onset of puberty. Pediatrics 2000;106:622-3.

14. Teilmann G, Pedersen CB, Jensen TK, Skakkebaek NE, Juul A. Prevalence and incidence of precocious pubertal development in Denmark: an epidemiologic study based on national registries. Pediatrics 2005;116:1323-8.

15. Herman-Giddens ME, Slora EJ, Wasserman RC, Bourdony CJ, Bhapkar MV, et al. Secondary sexual characteristics and menses in young girls seen in office practice: a study from the Pediatric Research in Office Settings network. Pediatrics 1997;99:505-12.

16. Elders MJ, Scott CR, Frindik JP, Kemp SF. Clinical work-up for precocious puberty. Lancet 1997;350:457-8.

17. Kaplowitz PB, Oberfield SE. Reexamination of the age limit for defining when puberty is precocious in girls in the United States: implications for evaluation and treatment. Drug and Therapeutics and Executive Committees of the Lawson Wilkins Pediatric Endocrine Society. Pediatrics 1999;104(Pt 1):936-41. 
18. Pedicelli S, Alessio P, Scirè G, Cappa M, Cianfarani S. Routine screening by brain magnetic resonance imaging is not indicated in every girl with onset of puberty between the ages of 6 and 8 years. J Clin Endocrinol Metab 2014;99:4455-61.

19. Bizzarri C, Spadoni GL, Bottaro G, Montanari G, Giannone G, et al. The response to gonadotropin releasing hormone ( $\mathrm{GnRH})$ stimulation test does not predict the progression to true precocious puberty in girls with onset of premature thelarche in the first three years of life. J Clin Endocrinol Metab 2014;99:433-9.

20. DeSanctis V, Corrias A, Rizzo V, Bertelloni S, Urso L, et al. Etiology of central precocious puberty in males: the results of the Italian Study Group for Physiopathology of Puberty. J Pediatr Endocrinol Metab 2000;13:687-93.

21. Atta I, Laghari TM, Khan YN, Lone SW, Ibrahim M, et al. Precocious puberty in children. J Coll Physicians Surg Pak 2015;25:124-8.

22. Bridges NA, Christopher JA, Hindmarsh PC, Brook CG. Sexual precocity: sex incidence and aetiology. Arch Dis Child 1994;70:116-8.

23. Chalumeau M, Chemaitilly W, Trivin C, Adan L, Breart G, et al. Central precocious puberty in girls: an evidence-based diagnosis tree to predict central nervous system abnormalities. Pediatrics 2002;109:61-7.

24. Choi KH, Chung SJ, Kang MJ, Yoon JY, Lee JE, et al. Boys with precocious or early puberty: incidence of pathological brain magnetic resonance imaging findings and factors related to newly developed brain lesions. Ann Pediatr Endocrinol Metab 2013;18:183-90.

25. FDA Drug Safety Communication: FDA evaluating the risk of brain deposits with repeated use of gadolinium-based contrast agents for magnetic resonance imaging (MRI) (Issued on 7-27-2015).

26. Oerter KE, Uriarte MM, Rose SR, Barnes KM, Cutler GB Jr. Gonadotropin secretory dynamics during puberty in normal girls and boys. J Clin Endocrinol Metab 1990;71:1251-8.

27. Houk CP, Kunselman AR, Lee PA. Adequacy of a single unstimulated luteinizing hormone level to diagnose central precocious puberty in girls. Pediatrics 2009;123:e1059-63.

28. Neely EK, Wilson DM, Lee PA, Stene M, Hintz RL. Spontaneous serum gonadotropin concentrations in the evaluation of precocious puberty. J Pediatr 1995;127:47-52.

29. Mateen FJ, Oh J, Tergas Al, Bhayani NH, Kamdar BB. Titles versus titles and abstracts for initial screening of articles for systematic reviews. Clinical Epidemiol 2013;5:89-95.

30. Stewart LA, Clarke M, Rovers M, Riley RD, Simmonds M, et al. Preferred Reporting Items for Systematic Review and Meta-Analyses of individual participant data: the PRISMA-IPD Statement. J Am Med Assoc 2015;313:1657-65.
31. Bosnjak J, Budisic M, Azman D, Strineka M, Crnjakovic M, et al. Pineal gland cysts-an overview. Acta Clin Croat 2009:48:355-8.

32. Motta S, Decimi V, Pincelli Al, Fraschini D, Grimaldi M, et al. Precocious puberty and empty sella syndrome in a girl cured of acute lymphoblastic leukemia. J Pediatr Endocrinol Metab 2011;24:1067-9.

33. Acharya SV, Gopal RA, Menon PS, Bandgar TR, Shah NS. Precocious puberty due to rathke cleft cyst in a child. Endocr Pract 2009;15:134-7.

34. STATA/MP (Version 14.0 for Windows). College Station, TX, USA: StataCorp.

35. Newcombe RG. Two-sided confidence intervals for the single proportion: comparison of seven methods. Stat Med 1998;17:857-72. Cochran 1954.

36. Cochran WG. The combination of estimates from different experiments. Biometrics 1954;10:101-29.

37. DerSimonian R, Laird N. Meta-analysis in clinical trials. Control Clin Trials 1986;7:177-88.

38. World Health Organization. WHO information for physician density. Available at: http://www.who.int/gho/countries/en/.

39. Light RJ, Pillemer DB. Summing up: the science of reviewing research. Cambridge, MA: Harvard University Press, 1984:x+191pp.

40. de Muinich Keizer SM, Mul D. Trends in pubertal development in Europe. Hum Reprod Update 2001;7:287-91.

41. Ng SM, Kumar Y, Cody D, Smith CS, Didi M. Cranial MRI scans are indicated in all girls with central precocious puberty. Arch Dis Child 2003;88:414-8; discussion 414-8.

42. Mogensen SS, Aksglaede L, Mouritsen A, Sørensen K, Main $\mathrm{KM}$, et al. Pathological and incidental findings on brain MRI in a single-center study of 229 consecutive girls with early or precocious puberty. PLoS One 2012;7:e29829.

43. Chalumeau M, Hadjiathanasiou CG, Ng SM, Cassio A, Mul D, et al. Selecting girls with precocious puberty for brain imaging: validation of European evidence-based diagnosis rule. J Pediatr 2003;143:445-50.

44. Cisternino M, Arrigo T, Pasquino AM, Tinelli C, Antoniazzi $F$, et al. Etiology and age incidence of precocious puberty in girls: a multicentric study. J Pediatr Endocrinol Metab 2000;13:695-701.

45. Kaplowitz PB. Do 6-8 year old girls with central precocious puberty need routine brain imaging? Int J Pediatr Endocrinol 2016;2016:9.

Supplemental Material: The online version of this article offers supplementary material (https://doi.org/10.1515/jpem-2018-0052). 